\section{Identification of Woody Plants with Implanted Microchips}

\author{
Kim D. Bowman
}

ADDITIONAL INDEX WORDs. rootstock improvement, Citrus sinensis, sweet orange, Carrizo citrange

SUMMARY. Secure identification of individual plants by some kind of labels in the field is an important part of many types of horticultural, plant science, and ecological research. This report describes implanted microchips as one method of plant tagging that is reliable, durable, and secure. This technology may be especially useful in long-term experiments involving perennial woody plants. Two methods are described for implanting microchips in citrus trees that would also be applicable to other woody plant species. One method of implanting microchips is demonstrated to have no deleterious effect on citrus tree growth through the first 18 months after implantation into the tree. Since microchips implanted beneath the bark will become more deeply embedded in wood as the plants grow, signal penetration through wood was evaluated and determined to be sufficient for long-term field utility. Implanted microchips are potentially useful for secure tagging of valuable or endangered plant species to deter theft by providing secure and conclusive identification.

$\mathrm{D}$ urable identification labels for individual plants is an important part of many research projects involving plants in agriculture and the environment. Although labeling of plants is only infrequently mentioned in discussions of breeding or other research programs, it is a criti-

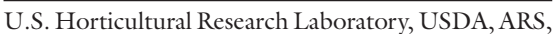
Ft. Pierce, FL 34945

The author gratefully acknowledges the equipment provided by Applied Digital Solutions and AVID Microchip I.D. Systems for this research project. USDA citrus rootstock development has been funded in part by grants from the Florida Citrus Production Research Advisory Council, Proj. Nos. 981-30I and 025-02I. Mention of a trademark, warranty, proprietary product, or vendor does not imply an approval to the exclusion of other products or vendors that also may be suitable. cal component of success in research (Layne, 1983). Plant labeling probably presents its greatest challenges in breeding, testing, and maintenance of woody plant species. The large increase in trunk and canopy diameter and frequent dieback, or pruning of branches during a plant lifetime, cause labels hanging on the tree to become lost or difficult to find. The long duration of the testing cycle allows plastic or painted-on plant labeling to disintegrate or become illegible. Labels nailed into the trunk frequently break off or become so deeply embedded within the growing trunk that they are unreadable. Identification of trees based on maps or global positioning system (GPS) location coordinates does not determine whether plants at a specific site are the original or replacement trees, an especially important issue at cooperator test plots with citrus trees. Testing of rootstocks for citrus and other grafted crops presents special challenges because of the typically very long-term nature of evaluation and the fact that few morphological traits are visible to confirm suspected identity.

Microchip transponders are one type of labeling that may be useful for specific applications with woody plants. These devices are very small, durable, long-lived, and emit a unique code signal when exposed to interrogation by an appropriate scanner device. Microchips have been used for several years to provide unique identity tags for pets, livestock, and experimental animals (Buguk et al., 1998; Caceci et al., 1999; Sorenson et al., 1995). The objective of this study was to evaluate the use of microchips for assigning a unique identity to citrus trees and other woody plants. Impact of implanted microchips on young tree health and growth was evaluated. We also measured penetration of scanner signal through wood, since microchips placed in the tree trunk will become progressively more deeply embedded in xylem tissue as the tree trunk grows in circumference.

\section{Materials and methods}

Microchip sizes. Six microchips of each type, AVID Code 14-mm (AVID Microchip I.D. Systems, Norco, Calif.), AVID Euro $12-\mathrm{mm}$, and ADS $12-\mathrm{mm}$ (Applied Digital Solutions, Palm Beach, Fla.) were measured with a digital caliper to evaluate size. The AVID Code 14-mm chip was 14.6 $\times 2.1 \mathrm{~mm}(0.575 \times 0.083$ inch $)$, the AVID Euro 12-mm chip was $12.4 \times$ $2.1 \mathrm{~mm}(0.488 \times 0.083$ inch $)$, and the ADS $12-\mathrm{mm}$ chip was $12.0 \times 2.0$ $\mathrm{mm}(0.472 \times 0.079$ inch $)$. All three types of microchip were encased by a glass coating to protect them from the environment.

Method of implantation. For smaller caliper trees, such as those typically found in citrus nursery settings, microchips were inserted with little damage to the trunk strength by using an upright T-cut above the graft union during a time when the tree was actively growing (Fig. 1). Although the microchips are larger in diameter than typical buds, the T-cutinsertion process was otherwise very similar to that for budding of citrus nursery trees.

EVALUATION OF TREE GROWTH. 'Early Gold' sweet orange (Citrus sinensis) was budded onto Carrizo citrange (C. sinensis $\mathrm{x}$ Poncirus trifoliata) rootstock in June 2001. Trees were potted in a steam-sterilized peat/ perlite/vermiculite mix (Pro-Mix BX; Premier Horticulture Inc., Red Hill, $\mathrm{Pa}$.) in 11-L (2.9 gal) nursery containers. Height of budding ranged from 15.5 to $22.0 \mathrm{~cm}$ (6.10-8.66 inches) above the growing substrate. Trees were grown in a warm greenhouse, with trimming and training to create a good commercial-quality citrus nursery tree. Potted trees were watered as needed, alternating between water and a water-soluble fertilizer mix, 20N-4.4P-16.6K (The Scotts Co., Marysville, Ohio) applied with a

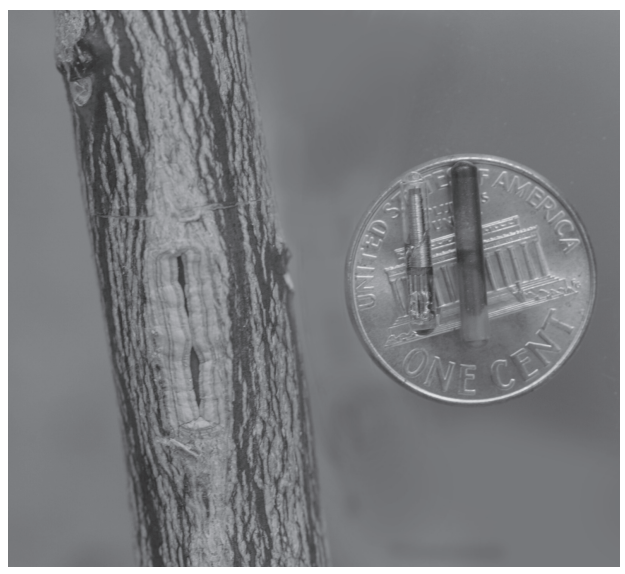

Fig. 1. Young sweet orange tree with microchip implanted by T-cut, nearly healed over, beside ADS 12-mm and AVID 14mm microchips. 
proportioner at a rate of $400 \mathrm{mg} \cdot \mathrm{L}^{-1}$ (ppm) N. No supplemental light was supplied. Maximum photosynthetic photon flux (PPF) in the greenhouse was $1000 \mu \mathrm{mol} \cdot \mathrm{s}^{-1} \cdot \mathrm{m}^{-2}$.

Height of first branching on individual trees ranged from 40 to $64 \mathrm{~cm}$ (15.7-25.2 inches) above the growing substrate and 23 to $45 \mathrm{~cm}$ (9.1-17.7 inches) above the graft union. In June 2002, tree calipers were measured at 12 $\mathrm{cm}$ ( 4.7 inches) above the graft union and sorted into four groups with approximately equal caliper means. Treatments applied in June 2002 to groups of seven trees each were: 1) none; 2 ) T-cut with no chip insertion; 3) T-cut with insertion of AVID Code 14-mm microchip; and 4) T-cut with insertion of ADS 12-mm microchip. Chip insertion was 4.5 to $7.0 \mathrm{~cm}$ (1.77-2.76 inches) above the budunion and 5.0 to $7.0 \mathrm{~cm}$ (1.97-2.76 inches) below the site for caliper measurement. All T-cut treatments were wrapped with budding tape immediately following insertion and unwrapped after 4 months. Experimental trees were maintained in the greenhouse nursery until planting into the field in St. Lucie County, Fla., at 10 months after chip insertion. Tree calipers $12 \mathrm{~cm}$ above the graft union and $5 \mathrm{~cm}$ below the graft union were measured the day before chip insertion and every 3 months for the next 18 months. A scanner was also used at each caliper date to verify continued microchip readability. Tree location was randomized in the greenhouse and in the field planting.

ReAdability THROUgh wOOD. The ability to accurately read microchips by scanners through different depths of wood was estimated by using three types of microchips, three types of scanners, and commercial lumber of pine (Pinus spp.) and oak (Quercus spp.). Microchips tested were AVID Code 14-mm, AVID Euro 12-mm, and ADS 12-mm. Scanners tested were AVID Breeder Reader, AVID PowerTracker II, and Destron-Fearing Portable Transceiver System Model 2100 $\mathrm{F}$ with $17.8-\mathrm{cm}$ ( 7 inches) portable antenna (Destron-Fearing Corp., St. Paul, Minn.). Board sections $45 \times 30$ $\mathrm{cm}(17.7 \times 11.8$ inches $)$ from lumber of pine and oak and ranging from $6 \mathrm{~mm}$ to $19 \mathrm{~mm}(0.24-0.75$ inch $)$ thickness were stacked in series between microchip and scanner to evaluate signal penetration. Maximum read distance through wood was determined for

Table 1. Comparison of growth for trees with no treatment (None), a T-cut and no implantation (Cut only), and two different sizes of implanted microchips (14and $12-\mathrm{mm}$ diameter $).{ }^{\mathrm{z}}$

\begin{tabular}{|c|c|c|c|c|c|c|c|c|}
\hline \multirow[b]{3}{*}{ Treatment } & \multicolumn{8}{|c|}{ Caliper of tree $(\mathrm{mm})$} \\
\hline & \multicolumn{4}{|c|}{ Scion (120 $\mathrm{mm}$ above union) } & \multicolumn{4}{|c|}{ Rootstock ( $50 \mathrm{~mm}$ below union) } \\
\hline & Initial & 3 mo. $^{y}$ & 9 mo. & $18 \mathrm{mo}$. & Initial & 3 mo. & 9 mo. & $18 \mathrm{mo}$. \\
\hline None & 10.14 & 11.46 & 13.09 & 26.97 & 15.82 & 17.43 & 19.31 & 38.77 \\
\hline Cut only & 9.84 & 11.29 & 13.37 & 25.62 & 15.47 & 16.96 & 19.48 & 37.67 \\
\hline AVID $14-\mathrm{mm}$ & 10.14 & 11.34 & 13.38 & 26.32 & 15.82 & 17.10 & 19.67 & 38.17 \\
\hline ADS 12-mm & 10.03 & 11.16 & 13.36 & 25.23 & 15.71 & 17.49 & 19.86 & 36.12 \\
\hline SE & 0.339 & 0.281 & 0.270 & 0.798 & 0.381 & 0.362 & 0.370 & 1.424 \\
\hline$P$ & 0.91 & 0.92 & 0.85 & 0.44 & 0.90 & 0.68 & 0.75 & 0.60 \\
\hline
\end{tabular}

${ }^{\mathrm{z}} 1.00 \mathrm{~mm}=0.0394$ inch.

ymo. = months after treatment.

six different microchips of each type. After readings were completed with dry lumber of pine and oak, the pine lumber was soaked in water for $22 \mathrm{~h}$ and signal penetration re-evaluated for wet wood.

The data for tree growth and signal penetration through wood were tested by analysis of variance using Statistica (version 6.0; StatSoft, Tulsa, Okla.). Duncan multiple range test was used for mean comparison within columns when the F-test was significant at $P$ $<0.05$.

\section{Results}

Performance in trees. All the trees used for the implant experiment were healthy in appearance throughout the 10 months they were held in the nursery after chip implantation and then the first 8 months in the field. The T-cut containing the chip generally was completely healed over by the tree within 6 months after chip insertion. Tree caliper was unaffected by an upright-T cut or implantation of either a 14- or $12-\mathrm{mm}$ microchip through the first 18 months (Table 1). All implanted microchips of each type remained readable by scanner (AVID PowerTracker II for the AVID chips, and Destron-Fearing $2100 \mathrm{~F}$ for the ADS chips) throughout the 18 months following implantation. For larger nursery trees and field trees, another method of inserting microchips was examined. For stem sections greater than $2.5 \mathrm{~cm}(1.00$ inch) diameter, microchips were easily inserted into the trunk after drilling a $2.4 \mathrm{~mm}$ (0.094 inch) diameter hole about $1.4 \mathrm{~cm}$ (0.55 inch) or more deep (Fig. 2).

SignAL PENETRATION THROUGH wooD. Distance that microchips could be read through wood varied significantly due to differences in scanning devices (Table 2). The AVID Power Tracker II scanner read 14- $\mathrm{mm}$ microchips through about $14.0 \mathrm{~cm}(5.5$ inches) of dry pine, while the AVID Breeder-Reader scanner read the same microchips only through $5.8 \mathrm{~cm}(2.28$ inches). There were equipment compatibility limitations, such that only the scanner-microchip combinations indicated in Table 2 could be studied. Small but significant differences in penetration through wood were also noted as relates to wood type, wood moisture, and microchip size. Significant interference with reading of microchips was noted from large metal objects in the vicinity, even if

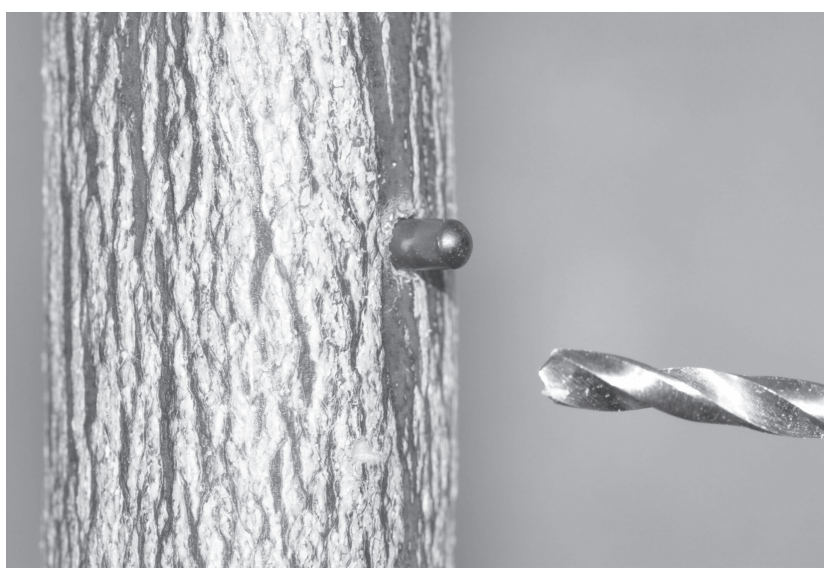

Fig. 2. Young sweet orange tree with AVID 14-mm microchip partially inserted into drilled hole beside a 2.4- $\mathrm{mm}$ (0.094 inch) drill bit. 
Table 2. Maximum read distance through oak and pine wood for four different microchip-scanner combinations. ${ }^{\mathrm{z}}$

\begin{tabular}{llccc}
\hline & & \multicolumn{3}{c}{ Maximum read distance $(\mathrm{mm})$ through: } \\
\cline { 3 - 5 } Microchip $^{\mathrm{y}}$ & Scanner & Dry oak & Dry pine & Wet pine \\
\hline Avid Code 14-mm & Breeder Reader & $54.0 \mathrm{c}$ & $58.2 \mathrm{c}$ & $51.2 \mathrm{c}$ \\
Avid Code 14-mm & Powertracker II & $122.0 \mathrm{a}$ & $139.8 \mathrm{a}$ & $119.2 \mathrm{a}$ \\
Avid Euro 12-mm & Powertracker II & $110.1 \mathrm{~b}$ & $124.0 \mathrm{~b}$ & $106.3 \mathrm{~b}$ \\
ADS 12-mm & D-F 2100F & $123.8 \mathrm{a}$ & $122.4 \mathrm{~b}$ & $128.0 \mathrm{a}$ \\
SE & & 2.2 & 2.5 & 1.7 \\
$P$ & & $<0.00001$ & $<0.00001$ & $<0.00001$ \\
\hline
\end{tabular}

${ }^{2} 1.00 \mathrm{~mm}=0.0394$ inch

'Microchips and scanners compared were models obtained from Avid and ADS companies, as indicated.

x Dry oak and dry pine were wood as obtained from a retail lumber distributer. Wet pine was soaked in water overnight. Mean separations for significant analysis of variance in columns were by Duncan's multiple range test at $P<0.05$.

they were not between the scanner and microchip.

\section{Discussion}

Microchips can be easily implanted into citrus and other woody species by insertion beneath the bark (like budding) when the tree is very young and actively growing, or by inserting them into small holes drilled in larger nursery plants or field trees.

Implanting of microchips in young citrus trees has no deleterious effect on young tree growth and would apparently have no reason to affect trees as they age. Microchips of the types examined in this study have no internal power supply (they are powered by the signal they receive from the scanner) and have been reported to last many years in animal applications (American Kennel Club, 2004; Buguk et al., 1998). While there could be unanticipated problems affecting microchip longevity in applications involving woody plants, it seems likely that the microchips will be very durable over long periods of time once they are embedded in woody tissue.

The factors that may most significantly limit the use of implanted microchips for woody plant identification appears to be cost and readability at a distance through the wood. Individual microchips may cost $\$ 25$ or more, although they can be much cheaper if purchased in quantity (Christiansen, 2001). Scanners for reading chips begin at about $\$ 250$ and up (Highfill, 1997), depending upon power and durability. Chip and scanner costs might be prohibitive for many potential applications. The distance for reading microchips through wood with the more powerful scanners would be adequate for reading microchips implanted in most woody plant species for 10 years or more. However, this presumes the location of the microchip in the tree can be easily standardized (such as just above the graft union for citrus trees) to minimize searching. Where a longer duration of reliable identification is desired, retagging with a new microchip every $10-15$ years may be necessary. Since distance of reading seems to be strongly influenced by scanner power and microchip size, better alternatives may be to use a more powerful scanner and/or a larger chip. Another improvement to the microchip system for applications to plant science might include constructing a microchip with a stronger casing than glass and developing a database system so that the unique coded identity of the microchip is directly translated into cultivar name and other relevant information about the individual plant by the scanner system.

Microchip tagging technology seems suitable for some types of critical and long term secure identification of woody plants. While there are many other alternatives available to keep track of tree identity, each of them has limitations regarding durability or application. Microchip technology appears attractive for use as a part of a tree rootstock breeding/testing process because of the need to maintain accurate identity for thousands of trees scattered in continually-evolving research plots through 15-20 years or longer and the difficulty or cost that is involved in conclusively identifying the rootstock of trees with a lost or uncertain identity. Microchip tags also appear to be of potential value as permanent markers of tree identity for other woody species used in research and commerce. Practical applications might include securely labeling valuable plant germplasm to reduce errors in propagation or deter theft of endangered species.

\section{Literature cited}

American Kennel Club. 2004. AKC companion animal recovery frequently asked questions. 15 June 2004. <http://akc. org/love/car/carfaq.cfm>.

Buguk, C., R.T. Ervin, and J. Eberspacher. 1998. Economic analysis of an alternative cattle identification system used to decrease hide damage. J. Amer. Leather Chemists Assn. 93:248-254.

Caceci, T., S.A. Smith, T.E. Toth, R.B. Duncan, and S.C. Walker. 1999. Identification of individual prawns with implanted microchip transponders. Aquaculture 180:41-51.

Christiansen, B. 2001. Microchip identification: High tech animal lifesavers. 15 June 2004. <http://www.saveourstrays. com/chips.htm>.

Highfill, C. 1997. Microchips: An idea whose time has come. Birds N Ways Pet Bird Mag., Ezine 15 June 2004. <http: www.birdsnways.com/wisdom/ww7eiii. htm>.

Layne, R.E.C. 1983. Hybridization, p. 48-65. In: J.N. Moore and J. Janick (eds.). Methods in fruit breeding. Purdue Univ. Press, West Lafayette, Ind.

Sorenson, M.A., M.S. Buss, and J.W. Tyler. 1995. Accuracy of microchip identification in dogs and cats. J. Amer. Veterinary Medical Assn. 207:766-767. 